\title{
Interactive comment on "Formation of a multi-translational reactivated ancient landslide in the Three Gorges Reservoir, China” by Shilin Luo et al.
}

\section{Elena Petrova (Editor) \\ epgeo@mail.ru}

Received and published: 16 February 2019

The manuscript investigates an interesting and relevant topic: the development of a reactivated ancient landslide located in the Three Gorges Reservoir (China). The manuscript gives a geological background of the region and a very detailed overview of Outang Landslide. However, sections of Methodology and Results, which are essential for scientific papers, are missing. Discussion section is not a real discussion. The manuscript needs a thorough check of the English. Both reviewers suggest to reject the manuscript.

The editor agrees with the reviewers and suggests to reject the manuscript in this ver- 
sion. The authors can completely revise the manuscript according to the reviewer comments and resubmit it to the NHESS again. The text has to be restructured: sections of NHESSD Methodology and Results have to be included in the manuscript. The description of the study area have to be shortened and reorganized. The Discussion section should really discuss the Results obtained by the authors. The English of the manuscript should be copyedited.

Interactive

comment

Interactive comment on Nat. Hazards Earth Syst. Sci. Discuss., https://doi.org/10.5194/nhess2018-399, 2019.

Printer-friendly version

Discussion paper 